\title{
Anaplastic large cell lymphoma with primary involvement of the skeletal muscle: A case report
}

\author{
ZONGYOU YANG ${ }^{1-3^{*}}$, YUEJU LIU ${ }^{1-3 *}$, FUQIAN GUO ${ }^{4}$, WEI CHEN $^{1-3}$, YINGCHAO YIN $^{1}$, \\ ZHAOYU CHEN ${ }^{1-3}, \mathrm{HAN} \mathrm{LI}^{1-3}$, YANG LUO ${ }^{1-3}$ and YINGZE ZHANG ${ }^{1-3}$ \\ ${ }^{1}$ Department of Orthopedic Center, Third Hospital of Hebei Medical University; \\ ${ }^{2}$ Key Orthopedic Biomechanics Laboratory of Hebei; ${ }^{3}$ Orthopaedic Research Institution of Hebei; \\ ${ }^{4}$ Department of Medical Imaging, Second Hospital of Hebei Medical University, Shijiazhuang, Hebei 050051, P.R. China
}

Received May 22, 2014; Accepted March 4, 2015

DOI: $10.3892 / \mathrm{ol} .2015 .3087$

\begin{abstract}
The present study reported the case of a patient with primary anaplastic large cell lymphoma (ALCL) occurring in the left major psoas. A 24-year-old male patient presented with one-month history of left lower back pain, which had been exacerbated for 10 days prior to admission. Magnetic resonance imaging (MRI) scans revealed an enlarged major psoas muscle that protruded into the inguinal region. The presence of an intense soft tissue mass on MRI scans, as well as the results of fine-needle aspiration biopsy and immunohistochemical analysis of the mass, may help establish an early diagnosis, allowing for the appropriate treatment strategy to be initiated.
\end{abstract}

\section{Introduction}

Lymphoma was one the first hemopathies to be identified, and at present, lymphoma exhibits incidence rates of 1.39 and 0.84 cases per 100,000 individuals in males and females in China, respectively (1). In 1985, Stein et al first identified anaplastic large cell lymphoma (ALCL), which is characterized by the strong expression of antigen Ki-1 (2). ALCL is classified as a non-Hodgkin lymphoma (NHL) derived from peripheral T-cells and is estimated to account for $2-3 \%$ of all lymphoid neoplasms, according to the World Health Organization (WHO) classification $(3,4)$. ALCL represents a group of diseases which are heterogeneous with regard to histology, phenotype, cytogenetics and clinical course and thus, diagnosis remains difficult $(5,6)$ and the treatment for ALCL varies considerably in different patients, involving the

Correspondence to: Dr Yingze Zhang, Department of Orthopedic Center, Third Hospital of Hebei Medical University, 139 Zi Qiang Road, Shijiazhuang, Hebei 050051, P.R. China

E-mail: corresponding2012@163.com

*Contributed equally

Key words: anaplastic large cell lymphoma, skeletal muscle, diagnosis
CCG-5941, AIEOP LNH-97 and BFM-95 protocols (7-9). The expression of the anaplastic lymphoma kinase (ALK) protein is the main characteristic used to classify ALCLs into two different systemic forms, which included the ALK-positive (ALK+) and ALK-negative (ALK-) tumors (8-11). ALKALCL is more clinically aggressive and predominantly occurs as advanced-stage disease in older patients (9-11). It has been reported that ALK+ ALCLs exhibit a predominance for the involvement of bone, bone marrow and subcutaneous tissue whereas ALK-ALCLs are more likely to invade the liver and the gastrointestinal tract (10). Although ALCL tends to invade extranodal sites (10), primary involvement of the skeletal muscle is extremely rare. The present study described the case of a 24-year-old male patient diagnosed with an ALK- ALCL originating in the left psoas muscle, suggesting that multiple examinations may help the early recognition and correct diagnosis of ALCL. Written informed consent was obtained from the patient.

\section{Case report}

A 24-year-old male patient was admitted to the Third Hospital of Hebei Medical University (Shijiazhuang, China) in March 2013 with one-month history of progressively increasing pain in the lower back, which had been exacerbated for 10 days. The patient had been initially treated for suspected strained back muscle with no alleviation of the symptoms. The pain radiated down the front of the left distal thigh three days before admission. No fever, night sweats or weight loss were reported, with the exception of the irregular sphincter disturbances. In addition, the patient had no previous medical history of trauma or cancer. Upon physical examination, a 15x7 $\mathrm{cm}$ elastic hard mass underlying the rib cage and protruding to the left inguinal region was detected. Furthermore, cervical, axillary and inguinal lymph node enlargement was detected. The muscle strength of the left lower limb was assessed by manual muscle testing according to Medical Research Council scale (12) and was determined to be grade 4 . Other vital signs were within the normal limits. Laboratory examinations performed upon admission revealed a white blood cell count of $3.98 \times 10^{9} / 1$ [normal, $(4 \sim 10) \times 10^{9} / 1$ ], C-reactive protein level of $18.52 \mathrm{mg} / 1$ (normal, $<8 \mathrm{mg} / \mathrm{l}$ ), platelet count of $121.7 \times 10^{9} / 1$ 

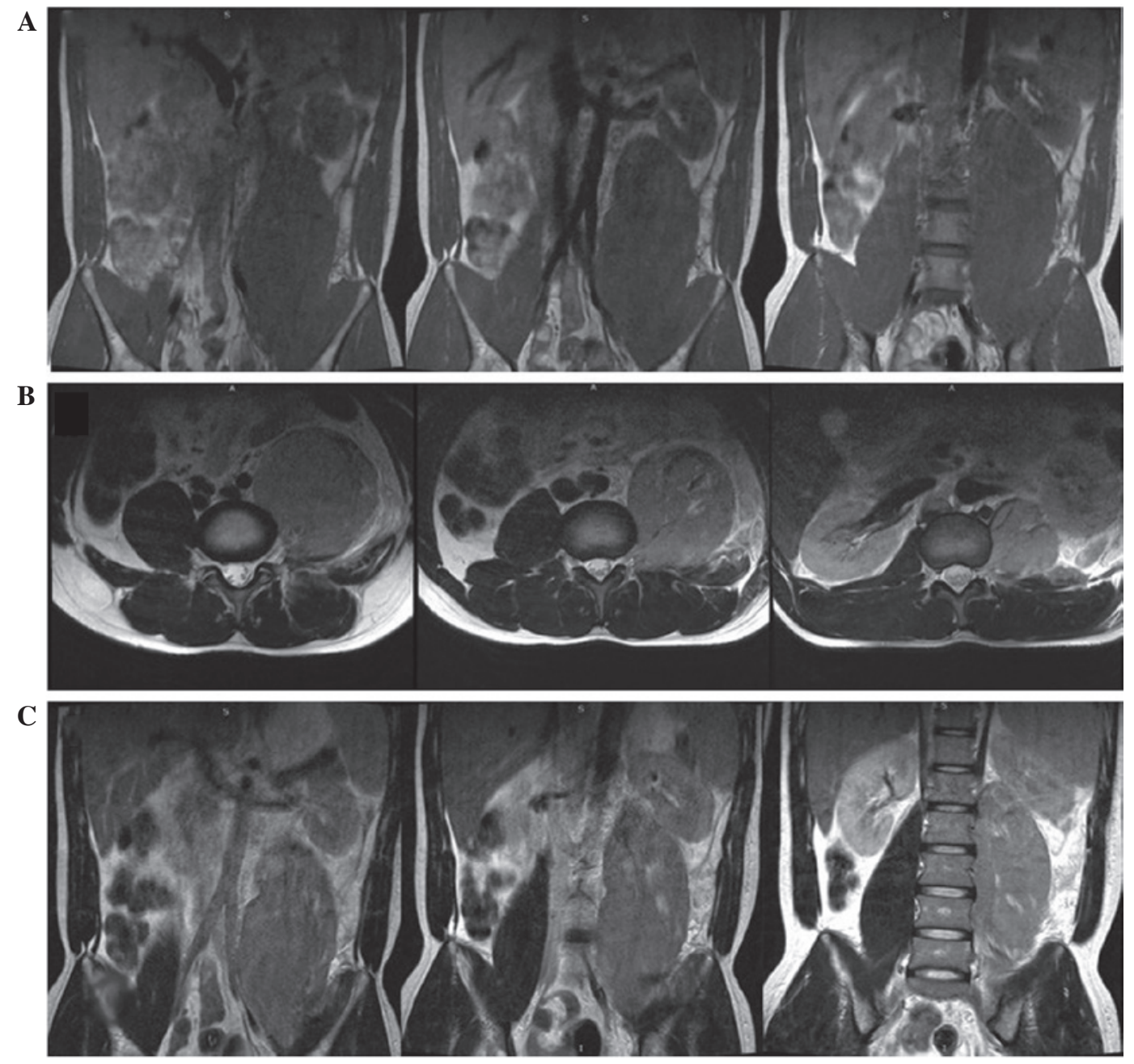

Figure 1. Magnetic resonance imaging scans of enlarged psoas. (A) Coronal $\mathrm{T}_{1}$-weighted images identified a hypointense mass in the left psoas. (B) Axial $\mathrm{T}_{2}$-weighted images revealed a relatively homogeneous mass of intermediate signal intensity. (C) Coronal fat-suppressed contrast-enhanced $\mathrm{T}_{1}$-weighted images are shown.

[normal, (100 300)x 10\%/1], and lactate dehydrogenase level of $1,958 \mathrm{U} / 1$ (normal, 104 245 U/l) (13). Using magnetic resonance imaging (MRI), swelling of the psoas muscle was identified (Fig. 1). Radiologically, the mass was initially considered to be a soft tissue tumor, such as rhabdomyosarcoma. Surgical resection of the left psoas muscle was performed, and subsequent histopathological examination revealed diffuse infiltration of large neoplastic cells with irregular mitosis (Fig. 2). Immunohistochemical analysis of the resected tumor was performed and the neoplastic cells were found to be positive for CD30 and leukocyte common antigen, whereas they were negative for ALK, CD15, paired box-5, Epstein-Barr virus (EBV), Melan-A and HMB-45. Therefore, the patient was diagnosed with ALK- ALCL at stage IV of the disease according to the Ann Arbor classification (14). Subsequently, three 21-day cycles of bortezomib $\left(1.3 \mathrm{mg} / \mathrm{m}^{2}\right.$, days 1 and 8$)$ and EPOCH [etoposide $\left(50 \mathrm{mg} / \mathrm{m}^{2}\right.$, days $1-4)$, adriamycin $\left(50 \mathrm{mg} / \mathrm{m}^{2}\right.$, days $\left.1-4\right)$, vincristine $\left(0.4 \mathrm{mg} / \mathrm{m}^{2}\right.$, days $\left.1-4\right)$, prednisone $\left(60 \mathrm{mg} / \mathrm{m}^{2}\right.$, days $\left.1-5\right)$ and cyclophosphamide $\left(750 \mathrm{mg} / \mathrm{m}^{2}\right.$, day 5$\left.)\right]$, and one 42 -day cycle of bortezomib $\left(1.3 \mathrm{mg} / \mathrm{m}^{2}\right.$, days 1 and 8$)$ and hyperCVAD [cyclophosphamide (300 $\mathrm{mg} / \mathrm{m}^{2}$, days 2-4), epirubicin $\left(16.6 \mathrm{mg} / \mathrm{m}^{2}\right.$, days $\left.5-7\right)$, intravenous vindesine (2 mg, days 5

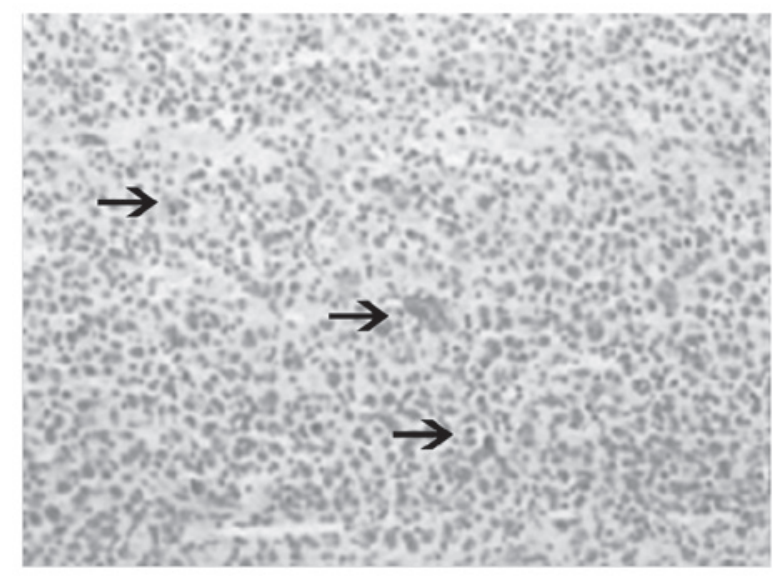

Figure 2. Histopathological analysis of the mass demonstrated invasion of tumor cells into the muscle fibers and pathological mitosis (arrows). $10 \%$ formalin; hematoxylin and eosin staining; magnification, $\mathrm{x} 40$.

and 12), dexamethasone (400 $\mathrm{mg}$, days $2-5$ and 12-16), methotrexate $\left(1,000 \mathrm{mg} / \mathrm{m}^{2}\right.$, day 23$)$ and cytarabine $\left(3 \mathrm{~g} / \mathrm{m}^{2}\right.$, days 24 and 25)] were administered. The chemotherapy was complicated by myelosuppression, however, the patient 
Table I. Previously reported cases $(n=8)$ of anaplastic large cell lymphoma with primary skeletal muscle involvement.

\begin{tabular}{lccccl}
\hline Author (ref.) & Year & ALK status & Age, years & Gender & Site \\
\hline Chim et al (19) & 1999 & N/A & 34 & M & Forearm \\
Ishii et al (20) & 2000 & ALK+ & 11 & F & Right upper arm, chest wall, left arm, left leg \\
Menon et al (21) & 2001 & N/A & 10 & F & Upper arm, thigh, chest wall \\
Liao et al (22) & 2005 & ALK- & 21 & M & Femoral muscle \\
Recavarren and Yang (23) & 2009 & ALK- & 83 & F & Psoas muscle \\
Driss et al (24) & 2009 & ALK+ & 8 & M & Buttock \\
Wu et al (25) & 2009 & ALK+ & 14 & M & Sarcospinal, lumbar and femoral muscles \\
Kounami et al (26) & 2012 & ALK+ & 14 & F & Psoas muscle
\end{tabular}

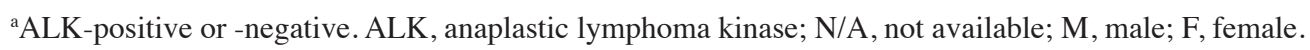

experienced sustained remission for around 6 months subsequent to discharge. The patient was lost to follow-up.

\section{Discussion}

ALK- ALCL, characterized by the strong expression of CD30 and its aggressive growth, is classified as a provisional entity of systemic type according to the 2008 WHO classification $(3,4)$. However, ALK- ALCL should be distinguished from other ALCL types, due to the different clinical features, treatment outcomes, and immunophenotypic and genetic markers used for the diagnosis of the disease (10).

Systemic ALCLs, among which ALK- ALCLs represent $15-50 \%$ of cases, account for $2-3 \%$ of NHLs $(3,4)$. ALCL may involve the extranodal organs, gastrointestinal tract, skin and central nervous system (15-17). This type of lymphoma rarely arises in the skeletal muscle, particularly with primary involvement. A 10-year study by Travis et al (18) described a $0.1 \%$ rate of primary lymphomas in the soft tissue and only eight cases with primary muscle involvement were identified in a review of 7,000 lymphoma patients. However, a search of PubMed (1950 to August 2013) using the search terms 'primar", AND 'anaplastic large cell lymphoma' AND 'muscle', identified only a small number of studies in English reporting primary skeletal muscle CD30+ ALCL (Table I) (19-26). To the best of our knowledge, the present study is the ninth reported case in the English literature.

The present study reported the case of a CD30+ and ALK- ALCL originating in the left psoas of a young adult. No particular risk factors have been previously identified for ALCL. At present, no convincing evidence exists suggesting that any viruses, including EBV and the human T-cell leukaemia/lymphoma virus family, may result in the development of NHL in humans. However, a previous study has demonstrated that T-cell ALCL risk was increased for patients with psoriasis and celiac disease suggesting that autoimmune disorders may lead to the development of this lymphoma (27).

At presentation, the possible diagnoses may include a broad spectrum of tumors, such as neuroectodermal tumor or sarcoma. Therefore, recognizing the MRI features of ALCL may promote the identification between primary skeletal muscle lymphoma and other soft-tissue neoplasms. The initial manifestations are typically abnormal muscle signal intensity and muscle enlargement. Generally, the neoplasms have slightly increased signal intensities compared with normal muscles on T1-weighted images and intermediate signal intensities compared with fat tissues on T2-weighted images (28). In addition, fine-needle aspiration (FNA) biopsy is normally conducted. However, considering the variable degree of cellular pleomorphism and number of anaplastic cells on the smears, the characteristic hallmark cells of ALCL are not always identified in a FNA biopsy sample, and an accurate diagnosis of ALCL is difficult. Therefore, performing ancillary tests, including immunohistochemical and flow cytometric analyses, may assist the diagnosis of ALCL (29). All the aforementioned examinations may help to confirm the diagnosis in order to initiate an appropriate chemotherapy regimen.

In conclusion, the present study represents a rare case of ALCL, primarily involving the skeletal muscle. This disease should be considered when establishing the diagnosis of a hematogenous disease in cases where the patient presents diffuse muscle swelling. The presence of a soft tissue mass on MRI scans, as well as the results of a FNA biopsy and immunohistochemical analysis of the mass, may help the early recognition and correct diagnosis of ALCL, allowing for the appropriate treatment strategy to be initiated.

\section{Acknowledgements}

The authors would like to thank Dr Shuaishuai Wu (Department of Orthopedic Center, Third Hospital of Hebei Medical University, Shijiazhuang, China) for the collection of the data.

\section{References}

1. Lu ZY and Zhong NS (eds.): Internal Medicine. In: Lymphoma. 7 th edition. People's Medical Publishing House, Beijing, pp617, 2009.

2. Stein H, Mason DY, Gerdes J, et al: The expression of the Hodgkin's disease associated antigen $\mathrm{Ki}-1$ in reactive and neoplastic lymphoid tissue: evidence that Reed-Sternberg cells and histiocytic malignancies are derived from activated lymphoid cells. Blood 66: 848-858, 1985.

3. Delsol G, Jaffe ES and Falini B: Anaplastic large cell lymphoma (ALCL), ALK-positive. In: WHO Classification of Tumours of Haematopoietic and Lymphoid Tissues. 4th edition. Swerdlow SH, Campo E, Harris NL, et al (eds). IARC, Lyon, pp312-316, 2008. 
4. Mason DY, Harris NL, Delsol G, et al: Anaplastic large cell lymphoma, ALK-negative. In: WHO Classification of Tumours of Haematopoietic and Lymphoid Tissues. 4th edition. Swerdlow SH, Campo E, Harris NL, et al (eds). IARC, Lyon, pp317-319, 2008.

5. Kadin ME: Primary Ki-1-positive anaplastic large-cell lymphoma: a distinct clinicopathologic entity. Ann Oncol 5 (Suppl 1): S25-S30, 1994.

6. Tilly H, Gaulard P, Lepage E, et al: Primary anaplastic large-cell lymphoma in adults: clinical presentation, immunophenotype, and outcome. Blood 90: 3727-3734, 1997.

7. Williams DM, Hobson R, Imeson J, Gerrard M, McCarthy K and Pinkerton CR; United Kingdom Children's Cancer Study Group: Anaplastic large cell lymphoma in childhood: analysis of 72 patients treated on the United Kingdom Children's Cancer Study Group chemotherapy regimens. Br J Haematol 117: 812-820, 2002

8. Lowe EJ, Sposto R, Perkins SL, Gross TG, Finlay J, Zwick D and Abromowitch M; Children's Cancer Group Study 5941: Intensive chemotherapy for systemic anaplastic large cell lymphoma in children and adolescents: final results of Children's Cancer Group Study 5941. Pediatr Blood Cancer 52: 335-339, 2009.

9. Pillon M, Gregucci F, Lombardi A, et al; NHL-Committee of the Italian Association of Pediatric Hematology and Oncology (AIEOP): Results of AIEOP LNH-97 protocol for the treatment of anaplastic large cell lymphoma of childhood. Pediatr Blood Cancer 59: 828-833, 2012 .

10. Savage KJ, Harris NL, Vose JM, et al; International Peripheral T-Cell Lymphoma Project: ALK-anaplastic large-cell lymphoma is clinically and immunophenotypically different from both ALK+ ALCL and peripheral T-cell lymphoma, not otherwise specified: report from the International Peripheral T-Cell Lymphoma Project. Blood 111: 5496-5504, 2008.

11. Falini B, Bigerna B, Fizzotti M, et al: ALK expression defines a distinct group of T/null lymphomas ('ALK lymphomas') with a wide morphological spectrum. Am J Pathol 153: 875-886, 1998.

12. Medical Research Council: Aids to the examination of the peripheral nervous system. Memorandum no. 45. Her Majesty's Stationery Office, London, 1976.

13. Chen WB and Pan X (eds.): Laboratory diagnosis. In: Diagnostics. 7th edition. People's Medical Publishing House, Beijing, pp25-440, 2009.

14. Carbone PP, Kaplan HS, Musshoff K, Smithers DW and Tubiana M: Report of the Committee on Hodgkin's Disease Staging Classification. Cancer Res 31: 1860-1861, 1971.

15. Zheng W, Song Y, Lin N, Tu M, Liu W and Zhu J: Primary gastrointestinal mantle lymphoma with massive bleeding: a case report and literature review. Chin J Cancer Res 25: 250-253, 2013.
16. Alaibac M, Bordignon M, Pennelli N, Aversa S, Fornasa CV and Chiarion V: Primary subcutaneous B-cell lymphoma: case report and literature review. Acta Derm Venereol 88: 151-154, 2008

17. Rao RN, Mishra D, Agrawal P and Kumar R: Primary B-cell central nervous system lymphoma involving fourth ventricle: A rare case report with review of literature. Neurol India 61: 450-453, 2013.

18. Travis WD, Banks PM and Reiman HM: Primary extranodal soft tissue lymphoma of the extremities. Am J Surg Pathol 11: 359-366, 1987.

19. Chim CS, Choy C and Liang R: Primary anaplastic large cell lymphoma of skeletal muscle presenting with compartment syndrome. Leuk Lymphoma 33: 601-605, 1999.

20. Ishii E, Honda K, Nakagawa A, Urago K and Oshima K: Primary CD30/Ki-1 positive anaplastic large cell lymphoma of skeletal muscle with der(17)t $(1 ; 17)(\mathrm{q} 11 ; \mathrm{p} 11)$. Cancer Genet Cytogenet 122: 116-120, 2000.

21. Menon BS, Maziah W, Samarendra M and Toha A: Pathological case of the month. Ki-1-positive anaplastic large cell lymphoma involving muscle. Arch Pediatr Adolesc Med 155: 411-412, 2001.

22. Liao WP, Dai MS, Hsu LF and Yao NS: Anaplastic large-cell lymphoma primarily infiltrating femoral muscles. Ann Hematol 84: 764-766, 2005.

23. Recavarren RA and Yang J: Cytomorphologic features of primary anaplastic large cell lymphoma of the psoas muscle: a case report and literature review. Diagn Cytopathol 38: 208-212, 2010.

24. Driss M, Abbes I, Mrad K, et al: Primary CD30/ALK-1 positive anaplastic large cell lymphoma of the skeletal muscle in a child. Pathologica 101: 97-100, 2009.

25. Wu L, Wang Y, Fu SL, Huang L, Tongji FC and Qi JY: Anaplastic large cell lymphoma with primary involvement of skeletal muscle: a rare case report and review of the literature. Pediatr Hematol Oncol 26: 142-149, 2009.

26. Kounami S, Shibuta K, Yoshiyama M, et al: Primary anaplastic large cell lymphoma of the psoas muscle: a case report and literature review. Acta Haematol 127: 186-188, 2012.

27. Derringer GA, Thompson LD, Frommelt RA, Bijwaard KE, Heffess CS and Abbondanzo SL: Malignant lymphoma of the thyroid gland: a clinicopathologic study of 108 cases. Am J Surg Pathol 24: 623-639, 2000

28. Chun CW, Jee WH, Park HJ, et al: MRI features of skeletal muscle lymphoma. AJR. Am J Roentgenol 195: 1355-1360, 2010.

29. Hudacko R, Rapkiewicz A, Berman RS and Simsir A: ALK-negative anaplastic large cell lymphoma mimicking a soft tissue sarcoma. J Cytol 28: 230-233, 2011. 